Article

\title{
Attitudes toward Sustainability and Green Economy Issues Related to Some Students Learning Their Characteristics: A Preliminary Study
}

\author{
Andrea Micangeli ${ }^{1,2, *}$, Vincenzo Naso ${ }^{1,2}$, Emanuele Michelangeli ${ }^{2}$, Apollonia Matrisciano ${ }^{3}$, \\ Francesca Farioli $^{1,2}$ and Nicola P. Belfiore ${ }^{1}$ \\ ${ }^{1}$ Department of Mechanical and Aerospace Engineering, Sapienza University of Rome, \\ Via Eudossiana, 18, Rome 00184, Italy; E-Mails: vincenzo.naso@ uniroma1.it (V.N.); \\ francesca.farioli@uniroma1.it (F.F.); nicolapio.belfiore@uniroma1.it (N.P.B.) \\ ${ }^{2}$ Inter-University Research Centre on Sustainable Development, CIRPS, \\ Sapienza University of Rome,Via Eudossiana, 18, Rome 00184, Italy; \\ E-Mail: emanuele.michelangeli@uniroma1.it \\ ${ }^{3}$ Engineering Faculty Didactic Management, Sapienza University of Rome, Via Eudossiana, 18, \\ Rome 00184, Italy; E-Mail: lia.matrisciano@uniroma1.it \\ * Author to whom correspondence should be addressed; E-Mail: andrea.micangeli@ uniroma1.it; \\ Tel.: +39-338-815-3787.
}

Received: 21 February 2014; in revised form: 4 April 2014 / Accepted: 7 May 2014 / Published: 28 May 2014

\begin{abstract}
The present paper proposes and describes a new method, called L2A (listen-to-apprise), conceived of in order to improve the commitment of all the participants involved in an educational process specifically dedicated to sustainability and the green economy. The first stage consists in listening to the students and, when possible, in listening to the environment, the people, and the territory, while, in the second stage, the acquired information is used to exploit everyone's talents and to achieve the maximum advantage and satisfaction for all. The first phase of L2A is mainly dedicated to listening to the students via the submission of an on-line questionnaire that measures their learning preferences, self-efficacy and sensitivity to the themes of sustainability and the green economy. The investigation has been extended from Italy to Honduras, where the authors are involved in the development of major projects concerning sustainability. The results of the survey have been analyzed by means of standard significance and correlation analysis, and therefore, significant differences among the groups and correlations within each group have been detected. The results have been discussed in order to explain how the L2A method
\end{abstract}


works and how useful and powerful a tool it could be to improve teaching, learning and practical activities.

Keywords: sustainability; green economy; students learning characteristics; L2A; self-efficacy; multiple intelligence inventory

\section{Introduction}

Sustainability has become a crucial aspect of social and economic development $[1,2]$, and the related ideas and theories deserve a large and detailed dissemination, especially (for under- and post-graduate students) in terms of education.

The challenges posed by global environmental changes and their associated socio-economic problems are persistent problems of unsustainability; they are complex and require urgent action and, mainly, a shift in our predicament. This change is required also within our academic institutions with regard to institutional structures, behavioral patterns and the educational setting. Inflexible academic institutions, rooted in traditions and old techniques, resistant to engaging in creating knowledge for action, are rather inadequate to address the rise of present and future problems. Primary educational challenges are supposed to develop new ways of thinking, skills and attitudes.

A number of studies and initiatives (examples of these activities have been provided by the School of Sustainability at Arizona State University, the Graduate Program in Sustainability Science, GPSS, at University of Tokyo, the Lund University International Master's Program in Environmental Studies and Sustainability Science (LUMES), the Lund University Centre of Excellence for Integration of Social and Natural Dimensions of Sustainability (LUCID) and, finally, by the South Africa initiative Sustainability and Community study abroad program in Stellenbosch.) recently presented [3], have contributed with the development of a coherent set of core competencies. Among those being proposed: systems thinking, strategic, anticipatory, normative and interpersonal skills that foster teamwork, leadership, communication and negotiation skills and system thinking [4,5]. These programs do not just educate professionals for green jobs, but train systemic-problem solvers, change agents and transition managers [4,6]. Pedagogies to deliver sustainability competences must include learning about envisioning change and developing evidence-based solution strategies through rigorous research. Soft skills are also required: empathy, sensitivity and facilitation are crucial qualities in order to work with communities and to solve problems.

The process of learning new issues related to sustainability and the green economy has been the object of a great number of recent investigations. For example, in 2013, Sibanda [7] argued that the expansion and adoption of green knowledge systems should be treated with urgency in institutions of higher education and used a survey technique to ascertain the use of green knowledge

in teaching and learning among students in the College of Law and Management Studies at UKZN (University of KwaZulu-Natal). The results showed that, although the students were familiar with 
climate change issues, they did not follow green practices, because of the convenience of using printed materials, the high cost of electronic gadgets and resistance to change to newer techniques.

Education for sustainability (EfS) has became a crucial issues in order to raise awareness, increase motivation, for both individuals and organizations, to develop and implement innovative solutions. Hence, an incredible variety of different contributions were offered from different countries.

In 2013, Scott [8] described the development of a photography competition to raise awareness of education for sustainability (EfS) in the curriculum and also as a co-curricular activity. Brundiers et al. [9] reviewed the position of a trans-academic interface manager (TIM) supporting participatory sustainability research and education efforts and proposed an educational approach for how to train students in becoming a TIM, providing practical guidance to universities on how to organize these critical endeavors more effectively and to offer students an additional career perspective. Bielefeldt [10] provided examples of different methods that were used at one institution to educate engineering students about sustainability and offered data that supported the achieved results: case studies, software tools, lectures, active learning, targeted homework assignments and term projects. Barth and Burandt [11] presented three mini case studies of educational praxis and discussed critically some opportunities and threats of the related e-learning settings. These cases were used to asses and elaborate the characteristics of e-learning environments that support competence development and education for sustainability. Brundiers and Wiek [9] introduced a framework for problem and project-based learning (PPBL) courses in sustainability and reviewed PPBL practice in six programs around the world (Europe, North America, Australia). In this contribution, data were collected through semi-structured qualitative interviews with course instructors and program officers. Results indicated that the reviewed PPBL courses were of high quality and carefully designed.

In 2012, Ofei-Manu and Shimano [12] discussed a business-school collaborative learning partnership in the Regional Centre of Expertise (RCE) on Education for Sustainable Development (ESD) in Greater Sendai and proposed a conceptual framework for multi-stakeholder, ESD-based social learning within the RCE with the aim of enabling the creation of a sustainability-literate society.

In 2011, Wolf et al. [13] used the concept of unconferencing, a method for organizing social learning, which could be suitable for triggering sustainability learning processes. They also presented a case study on the application of unconferencing in a large Swiss University (namely, in Eidgenössische Technische Hochschule Zürich), where an unconference was conducted to engage students, academics, staff and external experts in a mutual learning process aimed at the development of project ideas for reducing its CO2 emissions. Rojas et al. [14] presented a community-based action research project (Think\&EatGreen@ School) aiming to foster food citizenship in the City of Vancouver and to develop a model of sustainable institutional food systems in public schools.

In 2010, Blewitt [15] reviewed, critically, the results obtained after the first year of operation of the new Lifelong Learning Network Consortium on Sustainable Communities, Urban Regeneration and Environmental Technologies established and led by the Lifelong Learning Centre at Aston University. In addressing the opportunity of sustainable lifelong learning, it was argued that the adopted networked learning could prefigure a new model for lifelong learning and sustainable education that renders the city itself a creative medium for transformative learning and sustainability. Hansmann [16] clarified the 
concept of sustainability learning and specifically analyzed motivational aspects. This contribution also explained the two-fold role, in which motivations act as determinants and targeted outcomes of sustainability learning processes, and the outstanding role that cooperation, hence cooperative motivation, plays in sustainable development.

The aim of the present investigation is supporting the process of the identification of the best set of pedagogies when preparing a sustainability educational program. A survey is the means used in order to acquire information about some learning characteristics and the preferences of the students. Then, the results of the survey have provided indications for tailoring pedagogies to the students' learning characteristics, with the target of being more effective in transmitting those skills, attitudes and ways of thinking that enable them to operate properly in a sustainable society.

\section{Teaching and Learning about Sustainability}

Most of the concepts related to sustainability and the green economy are rather complex to transmit to a class, one reason, among a huge number, being the fact that these issues are new to most students. Hence, the learning process may be slow and difficult.

Generally speaking, the educational process cannot be separated from the social and psychological context. In some previous contributions, the authors of the present paper attempted to take into account the variety and the complexity of the variables that most affect the learning process in academic structures. In 2000, they suggested a possible way of improving teaching effectiveness in some courses of Sapienza University [17]. Some of these contributions gave suggestions about new emerging professions in higher education and about new efficient procedures to be adopted in course planning and managing [18]. Later, the research group focused its attention on the efficiency of the didactic methods, and some experimental investigations were planned, involving cognitive styles, learning styles and preferences, as well as some other learning preference inventories [19]. In these investigations, great importance was given to the role played by information technology in contemporary education. This topic stimulated some new ideas, and consequently, a more ambitious project was attempted, where the verbal and mathematical learning capabilities of a neural network were compared in different conditions [20]. Some years later, the idea of a website supporting students led to an early version of a website called KinSynth (actually the web site is located at http://dima.uniroma1.it/kinsynth/), which was compared to other similar initiatives in the field of the dynamic analysis of multi-body systems. Furthermore, a correlation analysis between students cognitive styles and their attitude to join kinematic and dynamics open source code projects was also completed, and some interesting results were obtained [21].

The themes of sustainability are even more difficult to apply to such educational process, especially if proposed to different traditions and cultures. Hence, the present contribution has been dedicated to the acquisition of some information about how different student groups react to the inclusion of sustainability and green economy issues within their curricula and how such reactions are related to some of their learning preferences and self-efficacy level. Actually, there is no experimental data or evidence from the literature about any correlation between self-efficacy and sustainability or the green economy. Hence, this contribution tries to fill this gap, because self-efficacy has proven to be very 
effective for learning and teaching strategies (see, only for representative examples, the papers [22-24]), and so, the perception of an activity related to sustainability and the green economy could be correlated to self-efficacy. Furthermore, a deep understanding of the relations between the students' learning preferences and style, their self efficacy and their sensitivity to the importance of sustainability and the green economy is helpful for two main reasons.

- In higher education, the didactic management becomes aware of important students' characteristics, and so, it acquires knowledge about how to:

(1) Develop promising and effective teaching methods for the class;

(2) Develop didactic methods specifically dedicated to the themes of sustainability and the green economy;

(3) Suggest original activities that are in tune with the students learning preferences;

(4) Assign activities to the students with the best match between role and skill;

(5) Develop orientation programs for young people who are willing to join the course;

(6) Develop programs of evaluation that take into account the students' characteristics;

(7) Increase the students' satisfaction and, hopefully, reduce the number of students who abandon the curricula (this affects also the institution's position in the international ranks, with good economic feedback, both by public and private institutions);

- In society, large projects may have a great impact on a city or on a industrial or agricultural region; the reaction from the territory is very important to the project's success, and so, surveys and questionnaire are often submitted to a sample of the population. However, their answers may be affected by their different cognitive styles that they are applying to the perception of the project. For this reason, the correlation methods presented herein can be used as an example in order to improve the quality of the surveys and their effectiveness by:

(1) Including questions related to cognitive styles and learning preference in the appropriate contest;

(2) Correlating the learning preferences to the inclination to accept the program;

(3) Increasing people's participation level in the program.

In order to achieve these ambitious scopes, the research group has created a questionnaire that has been presented on an institutional website at Sapienza University of Rome. This questionnaire has helped to understand the students' perception of several crucial concepts that play an important role in learning about sustainability. For such a purpose, nine different dimensions have been introduced and then analyzed: two are related to sustainability, one is related to self-efficacy [25] and six are related to a selection of learning preferences inspired by Gardner's Multiple Intelligence Inventory [26].

The questionnaire has been submitted, in anonymous form, to three groups of students, with similar basic characteristics, but living in different countries. Another difference in the groups' characterization was the presence (or not) of a course on energy sustainability in the study plan.

The new questionnaire has been built in order to measure, on-line, the above-mentioned peculiar characteristics, as well as the students self-efficacy level and their natural attitude toward joining sustainability studies and sharing their most important ideas and concepts. Technically, the project has 
been developed on the above-mentioned KinSynth website, which offers an open space for cooperation in code development. Thanks to this website, the codes written by teachers and students are published as open source for the students and the scientific community. The site is dedicated to a variety of topics of mechanical engineering, with special attention to topology and kinematics [27-33]. The adoption of the website allowed us to offer access to the questionnaire to people from all over the world.

As will be explained in the following sections, the questionnaire has been conceived also in order to understand the mutual relations between the students' characteristics and their attitude towards the new ideas brought by sustainability.

\section{The Adopted Questions and Dimensions}

The questionnaire presented to the students has been articulated in sets of multiple-choice questions, each one relating to one of the investigated dimensions.

\subsection{Dimensions Related to Sustainability and the Green Economy}

As stated by Rowe [34] (p. 324), by working on problems that were brought to higher education by cities, businesses, non-profit organizations [35], and other institutions, the students can test themselves in giving workable contributions to solutions and have a positive impact on the world through their academic learning [34] (p. 324). In this way, they will be more motivated to acquire the necessary competences to address sustainability problems in their future professional experience, both in the natural [36] and in the virtual environment [37].

Two dimensions have been selected in order to investigate the students' interest inside and outside academic life: (a) sustainability in education (SUST-EDU) and (b) green economy fields (GREEN-ECO). SUST-EDU is intended to be a measure of the level of interest to include sustainability issues in academic curricula. GREEN-ECO is intended to be a measure of the students' involvement in changing their daily life according to the practical application of sustainability, actually empowering a green economy in their countries. The questions are reported in the Appendix.

\subsection{Dimensions Related to the Multiple Intelligent Inventory}

According to the Theory of Multiple Intelligence [26], there are different forms of intelligence that can be clearly distinguished. It is not easy to declare if a type of ability, individually possessed or commonly shared, can be considered as an acknowledged intelligence or not. However, there are some selective criteria that can be used, among which, the appreciation of such an ability by the whole society in history, the existence of certain individuals that can be universally acknowledged as exceptionally gifted in that capability in such a way that they can be considered as genius, the loss of that ability due to localized brain damage and the possibility of developing symbolic expressions around that capability. Gardner's model, which is nowadays widely known also in non-technical literature, identifies a student's frame of mind, defined by seven distinct intelligences (verbal, logical-mathematical, musical, kinesthetic, visual, interpersonal and intrapersonal), which can be adopted as a personal learning profile to be applied to the academic environment. However, only six of these dimensions have been identified, as described 
in the following paragraphs, since a musical learning style was not investigated. The questions do not refer to a general frame of mind, but rather to the student's inclination to use a specific style related to a specific intelligence. Therefore, the variety of the multiple intelligences is herein investigated as an inventory model of independent learning preferences that can be adopted by the students. The following dimensions have been considered.

- INTRA (intrapersonal) evaluates the student's attitude toward thinking, studying, solving problems or even enjoying doing so by drawing resources from his inner personality.

- INTER (interpersonal) evaluates the student's attitude toward working, studying or enjoying the company of other people.

- LOGI-MATH (logical-mathematical) takes into account the student's attitude toward using logic and mathematics in a variety of situations, including the learning context.

- SPATIAL (spatial) measures the student's preference of didactic supports based on graphical tools, like diagrams, block charts, and so on; for this dimension, there are also elements of a the general attitude toward thinking spatially and of visualizing solid objects in space.

- KINES (bodily-kinesthetic) estimates the student's attitude toward using manual or other physical means as a support to learning or studying; the inclination toward manual or physical activities is also inquired.

- VERBAL (verbal-linguistic) concerns the student's inclination toward using reading as the preferred way of learning; it is also related to the student's inclination toward enjoying reading and writing in general (out of the classroom context).

\subsection{Dimension Related to Self-Efficacy}

Finally, self-efficacy has been investigated via the GSE, General Self-Efficacy Scale, (see the Free University of Berlin web page [38]), a 10-item psychometric scale designed to assess optimistic self-beliefs and the ability to cope with a variety of difficult demands in life. Self-efficacy is a measure of the individual's ability to complete tasks and reach goals and concerns one's personal belief regarding his or her power to affect situations, which makes this characteristic the image of how a person actually manages to face challenges competently. Putwain et al. [39] addressed the importance of assessing and developing, in higher education, the students' self-efficacy in relation to their independent study skills, since academic self-efficacy is a predictor of academic achievement and may play an important role in maintaining challenge appraisals to maintain pleasant emotions and better academic performance.

In this research, self-efficacy has been measured by means of a 10-item psychometric scale, as suggested by Schwarzer et al. [25].

\section{Results, Discussion and Practical Application}

This section presents the results obtained by analyzing the on-line survey submitted to the three following groups: 
G-I 51 Italian students enrolled at Sapienza University of Rome, attending the fourth or fifth course year of the Master Level Course in Engineering. These students have been selected by the criterion that they had chosen to enroll in a specific exam dedicated to sustainability.

G-II 16 Honduran students enrolled at the Engineering Department of Tegucigalpa, University of Honduras, and attending the fourth or fifth course year. These students did not have a specific exam dedicated to sustainability.

G-III This group has been referred to as the SET group, namely, sustainable energy technologies group. It is composed of 34 students enrolled to the fourth or fifth year of a specific course called, indeed, Sustainable Energy Technologies, class of 2013, offered by Sapienza University of Rome. The course program includes the analysis of the environmental impact of energy technologies and some case studies related to the sustainable application of such technologies in various continents $[35,36,40]$.

The following paragraph is dedicated to a direct comparison among the raw scores in the proposed dimensions. Then, two other paragraphs will follow, one of which is dedicated to the comparison between the groups, and to the correlation within the groups.

\subsection{The Raw Scores}

Figure 1 shows the raw average scores obtained by each group in every dimension. For each dimension (the raw score is calculated in such a way that), zero and 10 represent, respectively, a null or perfect adherence of the answers to a set of given stems. For each dimension, an average of four questions are proposed, except for SELF-EFFICACY, for which 10 questions are used. Between the total disagreement and perfect agreement, a score equal to five has been used as the reference point for a neutral opinion, which is neither disagree nor agree. The analysis of the difference must be done by using the level of significance, and therefore, the variance analysis has been invoked, as described in the following paragraph.

Figure 1. The histogram of the raw scores for the Italian Group I, G-I (white), Hondurian G-II (grey) and SET2013 G-III (dark grey).

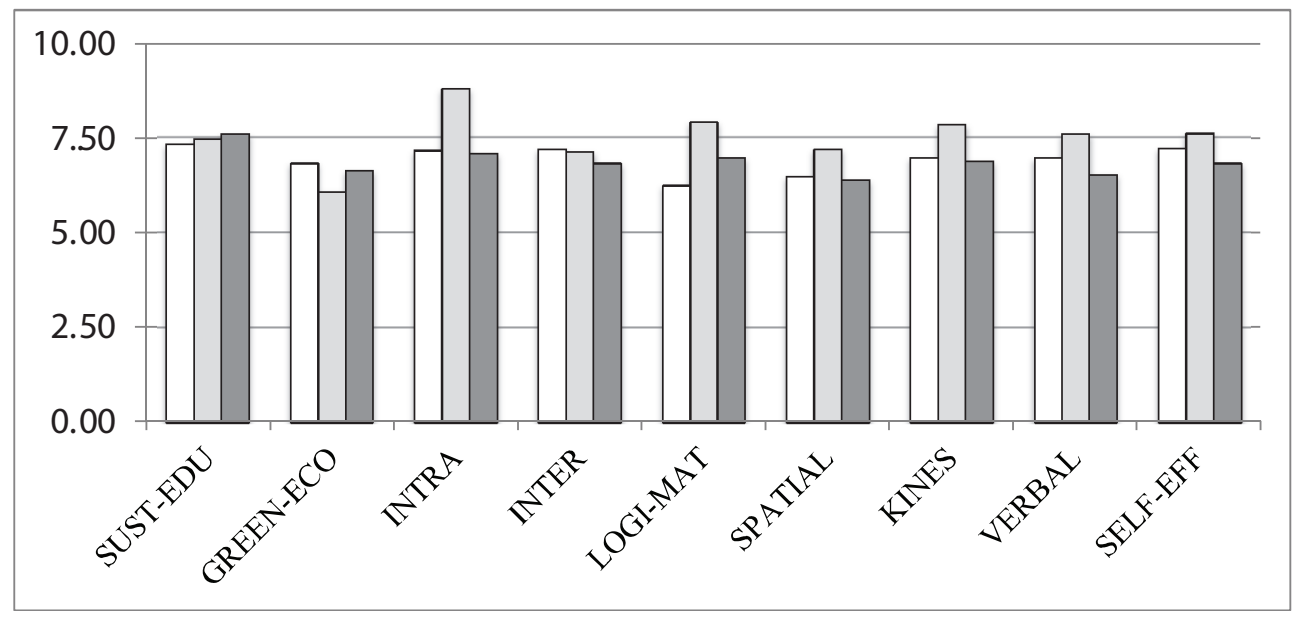




\subsection{Comparison among the Groups}

For the analyzed groups, different averages were found in many dimensions, as shown in Figure 1. However, only those which exceed the significance levels have to be considered.

For this reason, a null hypothesis, $\mathcal{H}_{0}$, has been established according to which the sample groups were extracted from the same population.

By imposing weak ( $\alpha=0.1$ ) or strong ( $\alpha=0.01$ ) probability levels, it turned out that the significant differences, according to the Student $t$-test and the proper degrees of freedom, were those reported in Table 1 and briefly discussed in the following list.

- SUST-EDU: no significant difference appears among the groups that concern the students' agreement on including more material and activities concerning sustainability. The three raw scores, however, are much higher than the neutral value, and this means that all three groups are favorably disposed about teaching more sustainability in class.

- GREEN-ECO: concerning the practical application of the selected aspects of the green economy in life, it appears that all the groups are susceptible to the theme, although the Italian students (Groups G-I and G-III) seem a bit more involved than the Hondurans ( $\alpha=0.1$ ).

- INTRA: the Honduran students show a greater inclination $(\alpha=0.01)$ to individual learning than the two groups of Italian students; this could be explained by considering the two different cultures;

- INTER: the G-I students seem to be stimulated by relational activities in learning better compared to G-III; this could be explained considering that G-I students did not participate in the SET Course, while G-III students did, and so, it is plausible that the former are better stimulated by group activities;

- LOGI-MAT: G-II (Honduran) students show considerable acquaintance with logical and mathematical tools in learning, more than G-I (strong) and G-III (weak). Actually, the G-I raw score in such a dimension is scarcely above the neutral score. Hence, for G-I, the lessons could be prepared in such a way that they do not make use of too much mathematics during presentations, while the G-II may prefer the quantitative, numerical or technical issues;

- SPATIAL and KINES: with respect to the two Italian groups, G-I and G-III, (but especially with respect to G-I), the Honduran students, G-II, seem to have a learning preference in which spatial and kinesthetic intelligence is more involved; these preference are greatly related to the practical aspects of learning, such as, for example, the use of hard models (paper or wood), diagrams, graphs, drawings and other visual means. As a consequence, this result suggests a greater use of visual materials and practical activities in G-II classes;

- VERBAL: although a weakly significant difference $(\alpha=0.1)$ appears between G-II and G-III, the preference of verbal intelligence (mainly reading) is quite uniform; this also matches some other previous investigations [19];

- SELF-EFFICACY: the Honduran students, G-II, got higher scores, on average, than those involved in the SET Course, G-III $(\alpha=0.01)$; the latter has a lower score than G-I with a weakly significance level; as pointed out in recent investigations [39], this information can be used for several purposes, such as, for example, organizing didactic management, counseling, participative and interactive learning, depending on the specific course. 
Generally speaking, the present investigation shows a way to improve the students' satisfaction and, eventually, success in courses that involve sustainability and the green economy. Analyzing the personal learning preferences (obviously related to the local culture and tradition) before deciding the teaching strategy is, therefore, a valid chance to improve the student comprehension of these important themes and to use a teaching strategy that better fits their characteristics.

Table 1. Significant differences between the groups.

\begin{tabular}{cccccccccc}
\hline GROUPS & SUST-EDU & GREEN-ECO & INTRA & INTER & LOGI-MAT & SPATIAL & KINES & VERBAL & SELF-EFF \\
\hline G-I $v$ s. G-II & - & weak & strong & - & strong & weak & weak & - & - \\
G-I $v$ s. G-III & - & - & - & weak & weak & - & - & - & weak \\
G-II $v$ s. G-III & - & - & strong & - & weak & weak & weak & weak & strong \\
\hline
\end{tabular}

Notes: INTRA, intrapersonal; LOGI-MAT, logical-mathematical; KINES, kinesthetic; SELF-EFF, self-efficacy; SUST-EDU, sustainability in education; GREEN ECO, green economy; INTER, interpersonal.

\subsection{The Correlation Analysis}

Within the single groups, it was possible to perform the correlation analysis among the dimensions. Such a kind of analysis is useful, for example, to understand if there are some characteristics that are mutually related (either positively or also negatively) in the group. A positive correlation between dimensions, say $a$ and $b$, means, for example, that, on average, if a student of the group has a high score on $a$, then he/she has also a high score on $b$.

Tables A1 and A4 refer to the group of Italian students, G-I, who have no specific courses on sustainability. Table A1 reports the correlation coefficient matrix, while Table A4 showing a matrix, whose non-null elements are the levels of significance for the corresponding elements of the correlation matrix. In particular:

- SELF-EFFICACY has been found to be strongly related to LOGI-MATH, SPATIAL and KINES;

- the two dimensions concerning sustainability are significantly correlated;

- SUST-EDU is correlated to the KINES preference;

- GREEN-ECO is correlated to LOGI-MATH, SPATIAL, KINES and VERBAL learning preference and also to SELF-EFFICACY.

Analogously, Tables A2 and A5 refer to the group of Honduran students, G-II. There are also negative correlations, such as those between the sustainability dimensions and the intrapersonal and interpersonal preferences.

There is a very strong correlation between SELF-EFFICACY and VERBAL preference $(r=0.893)$, and so, the corresponding scatter diagram has been presented in Figure 2.

Finally, the correlations between the SET2013 group, G-III, have been reported in Tables A3 and A6.

The correlation between SUST-EDU, GREEN-ECO and SELF-EFFICACY turns out to be highly significant, since those students of the three groups who are more interested in sustainability have a lifestyle increasingly sustainable (i.e., biking, buying food and items produced in their own region, etc.), thus being more self-efficient, as well. The correlation between the VERBAL variable and the SUSTEDU one within the SET2013 group, G-III, of students is strictly connected to the fact that they have 
already approached the theme of sustainability in their academic life: in fact, the SET course projects on renewable energy and sustainability in Europe, Asia, Africa and Latin America are examined [36,40]. This increases the attitude of this group of students towards studying and examining a higher number of data on this matter. The correlation between verbal and life-style preferences can be interpreted by observing that a higher inclination of students towards sustainable behaviors in daily life could be stimulated by personal reading and study, and so, they tend to examine issues in depth.

Figure 2. VERBAL vs. SELF-EFFICACY correlation diagram within the Honduran students.

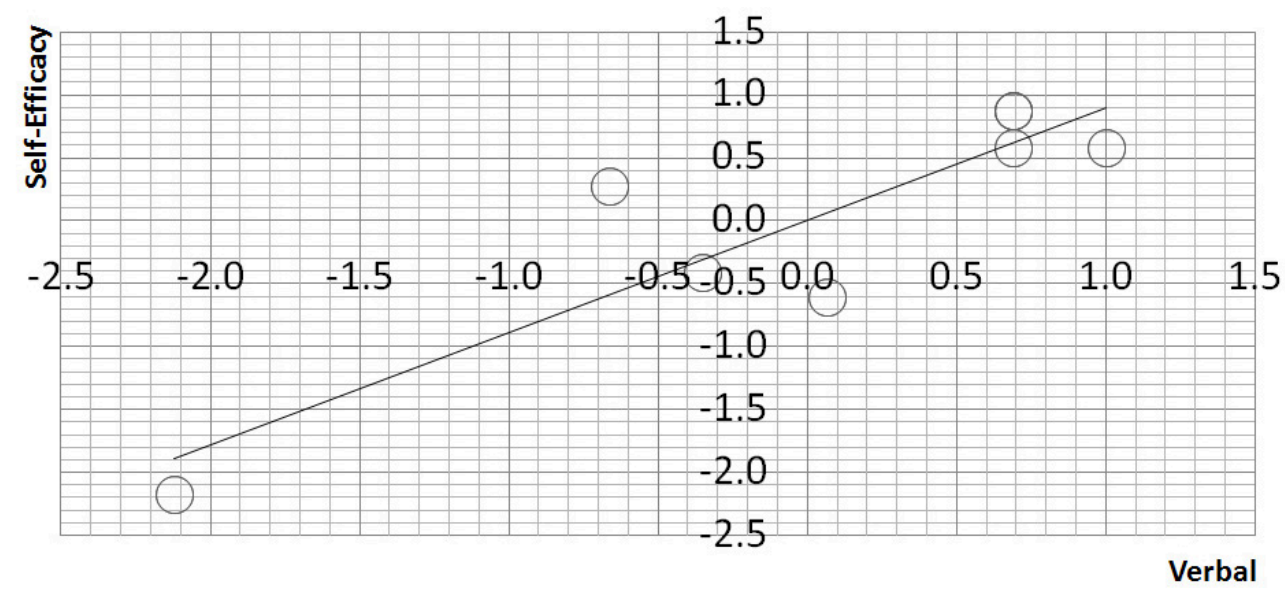

\subsection{Application}

The L2A method is believed to offer a useful tool to teachers and didactic managers who are involved in the development of interactive and group learning strategies in higher education institutions. The method is particularly tailored on the issues concerning the green economy and sustainability. As described in the previous section, during the listening stage, some statistical data are obtained, which allow one to understand some student learning preferences and predispositions and how these characteristics are related to the topics that are the object of teaching. These results give immediately fresh information about the most welcome teaching methods. However, L2A has been applied herein not only to improve teaching methods, but also to serve as a guide to prescribe the best interactive and the practical activities that support learning and the stimulate sensitivity to environmental issues.

Thanks to the results obtained by the listening stage, the research group involved in the present investigation had the opportunity to suggest and assign to the students important field activities that are peculiar to the educational program. These activities have been inspired by some works that have been recently pursued in order to develop: small-scale solar powered ORC (Organic Rankine Cycle) systems [41], thermal energy supply systems in emergency situations [42], hydrogen-rich gas production systems [43], membrane-free OSEC (On Site Electrolytic Chlorination System) systems [44], new solar integrated collector storage systems [45], post-earthquake rehabilitation of rural water systems [35], electricity displacement systems [46], web access-aided systems for disabled people [37] and water purification systems in the Middle East [36]. Hence, taking inspiration from the mentioned previous work, a list of activities has been tailored for the groups of students, G-I, G-II and G-III, since they 
are participating in a research and development major project concerning sustainability and the green economy, which is actually affecting about 40,000 beneficiaries in the territory.

This project concerns the actual electrification of an isolated rural area of Honduras, and so, it is composed of a plethora of activities, such as, for example, the design and installation of energetic systems, the training of users and maintainers, the disclosure and communication of commercial and economic best practices with respect to the environment and the study of the beneficiary local community. The research group decided to involve the three student groups in the following activities of the major project. The following activities have been assigned to small groups of students (from three to seven students).

$A_{1}$ teaching other students some issues concerning multi-source energy systems [47];

$A_{2}$ organizing and managing training activities concerning the energy systems for the benefit of the so-called local skilled managers [48];

$A_{3}$ organizing and managing training activities concerning the maintenance and repair of energy systems for the benefit of unskilled beneficiaries and users [49];

$A_{4}$ promotion of the use of biofuels for the reduction of the firewood consumption;

$A_{5}$ submission of a survey about sustainability to the project beneficiaries;

$A_{6}$ data harvesting and analysis from 10 meteorological stations in order to monitor climate change;

$A_{7}$ assessment, information and promotion, for the territory, of the biodiversity and cooperation with the Autonomous National University of Honduras (UNAH) for developing scientific knowledge about local biodiversity;

$A_{8}$ improvement of National Park' venue accommodations and tourist shelters;

$A_{9}$ management of a local radio station, broadcasting and creation of a network of young communicators and promoters who are endorsed to convey information about environmental issues;

$A_{10}$ design of a multi-source energy system composed of micro-hydro $(20 \mathrm{~kW})$ and photovoltaic energy $(10 \mathrm{~kW})[49]$;

$A_{11}$ practical installation of a multi-source energy system;

$A_{12}$ practical installation of 200 eco-ovens and 10 biodigesters with the capacity of $5 \mathrm{~m}^{3}$;

$A_{13}$ practical installation of two systems of chlorine self-production (OSEC) [50,51].

According to the L2A method, the activity roles and responsibilities have been assigned on the basis of the students characteristics in such a way that each group, or even each single student, is assigned to the activities that best fit the detected characteristics and preferences. Preference-to-activity mapping has been fully elaborated by means of the correspondence look-up Table A7, reported in the Appendix, which helps the groups and the single student with being assigned to a specific activity from the list. For example, the activity, $A_{9}$ (local radio), requires high sensibility and consciousness in sustainability in education and in the green economy, a great inclination to relate with people, a useful capability of elaborating data, a high verbal attitude and a certain self-confidence; those who match these characteristics have been considered to be assigned to the task. Practical activities $A_{11}, A_{12}$ and $A_{11}$ have been related to high scores achieved on the kinesthetic dimension, and so on. 


\section{Conclusions}

The students learning preferences and self-efficacy have been related to their inclination toward sustainability and the green economy. For this purpose, an on-line questionnaire has been submitted to three groups of students, two in Italy (G-I and G-III) and one in Honduras (G-II). The survey has given measures of seven dimensions: two dedicated to the attitude and sensitivity to sustainability and the green economy; six ones related to learning preferences based on the Multiple Intelligence Inventory; and one related to self-efficacy. Three different kinds of analysis of the results have been presented: analysis of the raw average scores between the different groups of students; analysis of the level of significance for the found difference, considering the probability levels and according to the Student $t$-test; and correlation analysis among the dimensions within the single groups. The results obtained in this investigation have shown that the optimization of the teaching strategy for a specific class is not the only target. Indeed, the method allows one to exploit students' capabilities according to their natural preferences and inclinations. The proposed method has been called L2A (listen to apprise), because it is based, firstly, on acquiring information from the students (listening) and, then, on enhancing their capability (appraise). It has been shown how the L2A method can be conveniently applied to a specific educational program that involves activities in major projects on a territory. Finally, this article suggests a way to explore and implement new methods to make the themes of sustainability and the green economy more popular in higher education and in society.

\section{Acknowledgments}

A special thanks to all Italian and Honduran students at Sapienza University of Rome (Italy) and Universidad Nacional de Honduras of Tegucigalpa (Honduras). Furthermore, Re.Te.ONG non-governmental organization (where ONG stands for Organizzazione Non Governativa), officially recognized by the Italian Ministry of Foreign Affairs and the European Union, and the Development and Cooperation Europe Aid Directorate-General are greatly acknowledged for supporting the project in Honduras.

\section{Appendix I}

\section{Questionnaire Stems Adopted for the Dimensions Related to Sustainability and the Green Economy}

In this section, the questionnaire stems related to the variables, SUST-EDU and GREEN-ECO, are presented. The stems are supposed to be either a direct question, a sentence to be concluded or a sentence with which to be in agreement.

\section{STUST-EDU}

04 Adding economical, social and environmental evaluations (when not required) to a technical study will double its cost, and therefore, you will consider it as...

11 I agree to increase my current curriculum in the cost and commitment to study, in order to add skills and models to augment the sustainability of my future job. 
20 The teaching of sustainability principles should be integrated into the curriculum in all disciplines and at all levels of schooling.

\section{GREEN-ECO}

10 I try to avoid purchasing goods from companies with poor track records on corporate social responsibility.

17 I walk or bike to places instead of going by car.

19 How many times a week do you buy and/or eat organic/local food?

21 Do you regularly recycle?

22 I have changed my personal lifestyle to reduce waste.

\section{Appendix II}

Correlation Tables

Table A1. Correlation Matrix for the group, G-I, of Italian students.

\begin{tabular}{cccccccccc}
\hline & SUST-EDU & GREEN-ECO & INTRA & INTER & LOGI-MATH & SPATIAL & KINES & VERBAL & SELF-EFF \\
\hline SUST-EDU & 1.000 & 0.286 & -0.034 & 0.211 & 0.152 & 0.203 & 0.238 & 0.034 & 0.058 \\
GREEN-ECO & - & 1.000 & 0.214 & -0.041 & 0.244 & 0.315 & 0.412 & 0.323 & 0.279 \\
INTRA & - & - & 1.000 & 0.273 & 0.172 & 0.227 & 0.308 & 0.393 & 0.201 \\
INTER & - & - & - & 1.000 & 0.069 & 0.277 & 0.149 & 0.155 & 0.089 \\
LOGI-MATH & - & - & - & - & 1.000 & 0.439 & 0.252 & 0.284 & 0.405 \\
SPATIAL & - & - & - & - & - & 1.000 & 0.510 & 0.130 & 0.511 \\
KINES & - & - & - & - & - & - & 1.000 & 0.236 & 0.373 \\
VERBAL & - & - & - & - & - & - & - & 1.000 & 0.238 \\
SELF-EFF & - & - & - & - & - & - & - & - & 1.000 \\
\hline
\end{tabular}

Table A2. Correlation Matrix for the G-II group of Honduran students.

\begin{tabular}{cccccccccc}
\hline & SUST-EDU & GREEN-ECO & INTRA & INTER & LOGI-MATH & SPATIAL & KINES & VERBAL & SELF-EFF \\
\hline SUST-EDU & 1.000 & 0.474 & -0.475 & -0.295 & 0.674 & 0.497 & -0.047 & 0.393 & 0.524 \\
GREEN-ECO & - & 1.000 & -0.534 & -0.569 & 0.770 & 0.788 & -0.182 & 0.630 & 0.647 \\
INTRA & - & - & 1.000 & 0.774 & -0.083 & -0.305 & 0.406 & -0.311 & -0.225 \\
INTER & - & - & - & 1.000 & -0.093 & 0.009 & 0.499 & 0.079 & -0.027 \\
LOGI-MATH & - & - & - & - & 1.000 & 0.767 & 0.080 & 0.577 & 0.776 \\
SPATIAL & - & - & - & - & - & 1.000 & 0.094 & 0.873 & 0.799 \\
KINES & - & - & - & - & - & - & 1.000 & 0.443 & 0.502 \\
VERBAL & - & - & - & - & - & - & - & 1.000 & 0.893 \\
SELF-EFF & - & - & - & - & - & - & - & - & 1.000 \\
\hline
\end{tabular}


Table A3. Correlation Matrix for the SET group, G-III.

\begin{tabular}{cccccccccc}
\hline & SUST-EDU & GREEN-ECO & INTRA & INTER & LOGI-MATH & SPATIAL & KINES & VERBAL & SELF-EFF \\
\hline SUST-EDU & 1.000 & 0.234 & 0.122 & 0.071 & 0.017 & -0.052 & 0.116 & 0.404 & 0.194 \\
GREEN-ECO & - & 1.000 & -0.145 & 0.076 & -0.016 & -0.257 & -0.198 & 0.332 & -0.084 \\
INTRA & - & - & 1.000 & 0.035 & 0.080 & 0.115 & 0.257 & -0.034 & 0.310 \\
INTER & - & - & - & 1.000 & 0.532 & 0.116 & 0.455 & 0.522 & 0.533 \\
LOGI-MAT & - & - & - & - & 1.000 & 0.285 & 0.314 & 0.418 & 0.179 \\
SPATIAL & - & - & - & - & - & 1.000 & 0.015 & -0.084 & 0.197 \\
KINES & - & - & - & - & - & - & - & 1.000 & 0.176 \\
VERBAL & - & - & - & - & - & - & - & - & 0.417 \\
SELF-EFF & - & - & - & - & - & - & - & 0.211 \\
\hline
\end{tabular}

\section{Appendix III}

\section{Correlation Levels of Significance}

Table A4. Correlation level of significance for found correlations for the group, G-I, of Italian students (critical levels $0.231,0.273,0.322$ and 0.354 , respectively, for the levels $0.10,0.05,0.02$ and 0.01$)$.

\begin{tabular}{|c|c|c|c|c|c|c|c|c|c|}
\hline & SUST-EDU & GREEN-ECO & INTRA & INTER & LOGI-MATH & SPATIAL & KINES & VERBAL & SELF-EFF \\
\hline SUST-EDU & - & 0.05 & - & - & - & - & 0.10 & - & - \\
\hline GREEN-ECO & - & - & - & - & 0.10 & 0.05 & 0.01 & 0.02 & 0.05 \\
\hline INTRA & - & - & - & 0.05 & - & - & 0.05 & 0.01 & - \\
\hline INTER & - & - & - & - & - & 0.05 & - & - & - \\
\hline LOGI-MATH & - & - & - & - & - & 0.01 & 0.10 & 0.05 & 0.01 \\
\hline SPATIAL & - & - & - & - & - & - & 0.01 & - & 0.01 \\
\hline KINES & - & - & - & - & - & - & - & 0.10 & 0.01 \\
\hline VERBAL & - & - & - & - & - & - & - & - & 0.10 \\
\hline SELF-EFF & - & - & - & - & - & - & - & - & - \\
\hline
\end{tabular}

Table A5. Correlation level of significance for found correlations for the group, G-II, of Honduran students (critical levels $0.426,0.497,0.574$ and 0.623 , respectively, for the levels, $0.10,0.05,0.02$ and 0.01$)$.

\begin{tabular}{cccccccccc}
\hline & SUST-EDU & GREEN-ECO & INTRA & INTER & LOGi-MATH & SPATIAL & KINES & VERBAL & SELF-EFF \\
\hline SUST-EDU & - & 0.10 & -0.10 & - & 0.01 & 0.05 & - & - & 0.05 \\
GREEN-ECO & - & - & -0.05 & -0.05 & 0.01 & 0.01 & - & 0.01 & 0.01 \\
INTRA & - & - & - & 0.01 & - & - & - & \\
INTER & - & - & - & - & - & - & 0.05 & 0.02 & 0.01 \\
LOGI-MAT & - & - & - & - & - & 0.01 & & 0.01 & 0.01 \\
SPATIAL & - & - & - & - & - & - & - & - & 0.10 \\
KINES & - & - & - & - & - & - & - & - & 0.01 \\
VERBAL & - & &
\end{tabular}


Table A6. Correlation level of significance for found correlations for group G-III (critical levels $0.231,0.273,0.322$ and 0.354 , respectively, for the levels, $0.10,0.05,0.02$ and 0.01 ).

\begin{tabular}{cccccccccc}
\hline & SUST-EDU & GREEN-ECO & INTRA & INTER & LOGI-MATH & SPATIAL & KINES & VERBAL & SELF-EFF \\
\hline SUST-EDU & - & - & - & - & - & - & - & 0.05 & - \\
GREEN-ECO & - & - & - & - & - & - & - & 0.10 & - \\
INTRA & - & - & - & - & - & - & - & - & 0.10 \\
INTER & - & - & - & - & -01 & - & 0.01 & 0.01 & 0.01 \\
LOGI-MAT & - & - & - & - & - & - & 0.10 & 0.02 & - \\
KINES & - & - & - & - & - & - & - & - & 0.02 \\
\hline
\end{tabular}

\section{Appendix IV}

\section{Practical Application of L2A: table of the activities}

Table A7. Dimensions-to-activities matching map table: $R$, highly recommended match; $r$, recommended match; $u$, useful match; -, no suggestions about matching.

\begin{tabular}{cccccccccc}
\hline ACTIVITY & SUST-EDU & GREEN-ECO & INTRA & INTER & LOGI-MATH & SPATIAL & KINES & VERBAL & SELF-EFF \\
\hline$A_{1}$ (teaching) & $R$ & - & - & $r$ & $r$ & - & - & $r$ & - \\
$A_{2}$ (training) & $u$ & $R$ & - & $r$ & $u$ & - & - & $r$ & - \\
$A_{3}$ (training) & - & $R$ & - & $r$ & - & $u$ & $R$ & $r$ & $r$ \\
$A_{4}$ (promotion) & $R$ & $R$ & - & $r$ & $u$ & - & $r$ & $R$ & - \\
$A_{5}$ (survey) & $R$ & $u$ & - & $R$ & $u$ & - & $u$ & $R$ & $R$ \\
$A_{6}$ (data) & $r$ & $u$ & - & - & $R$ & $r$ & - & - & - \\
$A_{7}$ (divulgation) & $R$ & $r$ & $r$ & $R$ & - & $u$ & - & $R$ & $R$ \\
$A_{8}$ (tourist) & $R$ & $r$ & - & $R$ & - & $u$ & - & $R$ & $R$ \\
$A_{9}$ (radio) & $r$ & $R$ & - & $R$ & $u$ & - & - & $R$ \\
$A_{10}$ (design) & - & - & $r$ & $R$ & $R$ & $R$ & - & $u$ & $u$ \\
$A_{11}$ (practice) & $R$ & $R$ & - & $R$ & $u$ & $R$ & $R$ & - & $R$ \\
$A_{12}$ (practice) & $R$ & $R$ & - & $R$ & - & - & $R$ & $R$ & $u$ \\
$A_{13}$ (practice) & $R$ & $R$ & - & $r$ & $u$ & - & $r$ & $u$ & $r$ \\
\hline
\end{tabular}

\section{Author Contributions}

The present paper is the result of the free, full and equal cooperation among all the Authors, who had the following roles and accomplished the following tasks. Andrea Micangeli, Project Leader and Coordinator, was the Corresponding Author. Vincenzo Naso, Team Leader, supervised the whole work. Emanuele Michelangeli, Project Participant, supported the activities with technical and engineering contents. Apollonia Matrisciano, Didactic Manager and Project Participants, supported the activities related to the Psychological aspects of the work. Francesca Farioli, Project Participant, supported the activities related to Sustainability. Nicola P. Belfiore, supervised the scientific aspects of the whole paper contents.

\section{Conflicts of Interest}

The authors declare no conflict of interest. 


\section{References}

1. Wiek, A.; Farioli, F.; Fukushi, K.; Yarime, M. Sustainability science: Bridging the gap between science and society. Sustain. Sci. 2012, 7, 1-4.

2. Wiek, A.; Ness, B.; Schweizer-Ries, P.; Brand, F.; Farioli, F. From complex systems analysis to transformational change: A comparative appraisal of sustainability science projects. Sustain. Sci. 2012, 7, 5-24.

3. Yarime, M.; Trencher, G.; Mino, T.; Scholz, R.; Olsson, L.; Ness, B.; Frantzeskaki, N.; Rotmans, J. Establishing sustainability science in higher education institutions: Towards an integration of academic development, institutionalization, and stakeholder collaborations. Sustain. Sci. 2012, 7, 101-113.

4. Wiek, A.; Withycombe, L.; Redman, C.; Mills, S. Moving forward on competence in sustainability research and problem solving. Environment 2011, 53, 3-12.

5. Wiek, A.; Withycombe, L.; Redman, C. Key competencies in sustainability: A reference framework for academic program development. Sustain. Sci. 2011, 6, 203-218.

6. Brundiers, K.; Wiek, A. Educating Students in Real-world Sustainability Research: Vision and Implementation. Innov. High. Educ. 2011, 36, 107-124.

7. Sibanda, M. Green knowledge in teaching and learning in higher education: Evidence from a South African university. Mediterr. J. Soc. Sci. 2013, 4, 709-715.

8. Scott, R. Education for Sustainability through a Photography Competition. Sustainability 2014, 6, 474-486.

9. Brundiers, K.; Wiek, A. Do We Teach What We Preach? An International Comparison of Problem- and Project-Based Learning Courses in Sustainability. Sustainability 2013, 5, 1725-1746.

10. Bielefeldt, A.R. Pedagogies to Achieve Sustainability Learning Outcomes in Civil and Environmental Engineering Students. Sustainability 2013, 5, 4479-4501.

11. Barth, M.; Burandt, S. Adding the "e-" to Learning for Sustainable Development: Challenges and Innovation. Sustainability 2013, 5, 2609-2622.

12. Ofei-Manu, P.; Shimano, S. In Transition towards Sustainability: Bridging the Business and Education Sectors of Regional Centre of Expertise Greater Sendai Using Education for Sustainable Development-Based Social Learning. Sustainability 2012, 4, 1619-1644.

13. Wolf, P.; Troxler, P.; Hansmann, R. Moving Universities: A Case Study on the Use of Unconferencing for Facilitating Sustainability Learning in a Swiss University. Sustainability 2011, 3, 875-896.

14. Rojas, A.; Valley, W.; Mansfield, B.; Orrego, E.; Chapman, G.E.; Harlap, Y. Toward Food System Sustainability through School Food System Change: Think\&EatGreen@ School and the Making of a Community-University Research Alliance. Sustainability 2011, 3, 763-788.

15. Blewitt, J. Deschooling Society? A Lifelong Learning Network for Sustainable Communities, Urban Regeneration and Environmental Technologies. Sustainability 2010, 2, 3465-3478.

16. Hansmann, R. Sustainability Learning: An Introduction to the Concept and Its Motivational Aspects. Sustainability 2010, 2, 2873-2897. 
17. Belfiore, N.P.; Di Benedetto, M.; Matrisciano, A. The mutual influences between technology and society: A contribution from the Mechanical Engineering Diploma Universitario of the University of Rome La Sapienza. In Proceedings of the International Symposium on Technology and Society, Rome, Italy, 8 September 2000; pp. 1-5.

18. Belfiore, N.; Di Benedetto, M.; Matrisciano, A.; Moscogiuri, C.; Mezzetti, C.; Recchioni, M. On some new emerging professions in the higher technical education. In System-Based Vision for Strategic and Creative Design, Proceedings of the 2nd International Conference on Structural and Construction Engineering, Rome, Italy, 23-26 September 2003; Bontempi, F., Ed.; University Rome La Sapienza; Volumes 1-3, pp. 2163-2169.

19. Matrisciano, A.; Belfiore, N.P. An investigation on cognitive styles and multiple intelligences model based learning preferences in a group of students in engineering. In Proceedings of the 2010 9th International Conference on Information Technology Based Higher Education and Training, ITHET 2010, Cappadocia, Turkey, 29 April-1 May 2010; pp. 60-66.

20. Belfiore, N.P.; Rudas, I.J.; Matrisciano, A. Simulation of verbal and mathematical learning by means of simple neural networks. In Proceedings of the 2010 9th International Conference on Information Technology Based Higher Education and Training, ITHET 2010, Cappadocia, Turkey, 29 April-1 May 2010; pp. 52-59.

21. Matrisciano, A.; Deplano, V.; Belfiore, N.P. Analysis of a teaching and learning method supported by open source codes and web activities. In Proceedings of the 2012 International Conference on Information Technology Based Higher Education and Training, ITHET 2012, Istanbul, Turkey, 21-23 June 2012.

22. Zimmerman, B.; Martinez-Pons, M. Student Differences in Self-Regulated Learning: Relating Grade, Sex, and Giftedness to Self-Efficacy and Strategy Use. J. Educ. Psychol. 1990, 82, 51-59.

23. Chemers, M.; Hu, L.T.; Garcia, B. Academic self-efficacy and first-year college student performance and adjustment. J. Educ. Psychol. 2001, 93, 55-64.

24. Bong, M. Between- and within-domain relations of academic motivation among middle and high school students: Self-efficacy, task-value, and achievement goals. J. Educ. Psychol. 2001, 93, 23-34.

25. Schwarzer, R.; Jerusalem, M. Generalized Self-Efficacy scale. In Measures in Health Psychology: A User's Portfolio; Weinman, J., Wright, S., Johnston, M., Eds.; NFER-NELSON: Windsor, UK, 1995; pp. 33-37,

26. Gardner, H. Frames of Mind: The Theory of Multiple Intelligences; Basic Books: New York, NY, USA, 1983.

27. Belfiore, N.P. Atlas of remote actuated bevel gear wrist mechanisms of up to nine links. Int. J. Robot. Res. 1993, 12, 448-459.

28. Belfiore, N.P.; Pennestrì, E. Automatic sketching of planar kinematic chains. Mech. Mach. Theory 1994, 29, 177-193.

29. Pennestrì, E.; Belfiore, N.P. Modular Third-Order Analysis of Planar Linkages with Applications; American Society of Mechanical Engineers, Design Engineering Division: Minneapolis, MN, USA, 1994; Volume 70-1, pp. 99-103. 
30. Pennestrì, E.; Belfiore, N.P. On the numerical computation of Generalized Burmester Points. Meccanica 1995, 30, 147-153.

31. Belfiore, N.P.; Pennestrì, E. An atlas of linkage-type robotic grippers. Mech. Mach. Theory 1997, $32,811-833$.

32. Belfiore, N.P. Distributed Databases for the development of Mechanisms Topology. Mech. Mach. Theory 2000, 35, 1727-1744.

33. Liberati, A.; Belfiore, N.P. A method for the identification of the connectivity in multi-loop kinematic chains: Analysis of chains with total and partial mobility. Mech. Mach. Theory 2006, 41, 1443-1466.

34. Rowe, D. Education for a Sustainable Future. Science 2007, 317, 323-324.

35. Micangeli, A.; Esposto, S. Post-earthquake rehabilitation of the rural water systems in Kashmir's Jehlum Valley. Disasters 2010, 34, 684-694.

36. Grego, S.; Micangeli, A.; Esposto, S. Water purification in the Middle East crisis: A survey on WTP and CU in Basrah (Iraq) area within a research and development program. Desalination 2004, 165, 73-79.

37. Federici, S.; Micangeli, A.; Ruspantini, I.; Borgianni, S.; Corradi, F.; Pasqualotto, E.; Olivetti Belardinelli, M. Checking an integrated model of web accessibility and usability evaluation for disabled people. Disabil. Rehabil. 2005, 27, 781-790.

38. General Self-Efficacy Scale (GSE). Available online: http://userpage.fuberlin.de/health/selfscal.htm (accessed on 3 May 2013).

39. Putwain, D.; Sander, P.; Larkin, D. Academic self-efficacy in study-related skills and behaviours: Relations with learning-related emotions and academic success. Br. J. Educ. Psychol. 2013, 83, 633-650.

40. Esposto, S.; Micangeli, A.; Grego, S. Sustainable water treatment and chlorine production in emergency conditions in South Iraq. Desalination 2004, 165, 123-132.

41. Villarini, M.; Bocci, E.; Moneti, M.; di Carlo, A.; Micangeli, A. State of art of small scale solar powered ORC systems: A review of the different typologies and technology perspectives. Energy Procedia 2013, 45, 257-267.

42. Micangeli, A.; Michelangeli, E.; Naso, V. Sustainability after the thermal energy supply in emergency situations: The case study of Abruzzi Earthquake (Italy). Sustainability 2013, 5, 3513-3525.

43. Sisinni, M.; Carlo, A.; Bocci, E.; Micangeli, A.; Naso, V. Hydrogen-rich gas production by sorption enhanced steam reforming of woodgas containing TAR over a commercial Ni catalyst and calcined dolomite as $\mathrm{CO}_{2}$ sorbentx. Energies 2013, 6, 3167-3181.

44. Dell'Era, A.; Zuccari, F.; Santiangeli, A.; Fiori, C.; Micangeli, A.; Orecchini, F. Energy optimisation and layout of a membrane-free OSEC system for the hypochlorite self-production in Developing Countries. Energy Convers. Manag. 2013, 75, 446-452.

45. Borello, D.; Corsini, A.; Delibra, G.; Evangelisti, S.; Micangeli, A. Experimental and computational investigation of a new solar integrated collector storage system. Appl. Energy 2012, 97, 982-989. 
46. Gualberti, G.; Alves, L.; Micangeli, A.; da Graa Carvalho, M. Electricity privatizations in Sahel: A U-turn? Energy Policy 2009, 37, 4189-4207.

47. Micangeli, A.; Evangelisti, S.; Sbordone, D. Alternative Energy: Solar Thermal Energy. In Encyclopedia of Environmental Management; Jorgensen, S.E., Ed.; Taylor and Francis Online: Oxon, UK, 2013; Chapter 26, pp. 241-257. Available online: http://www.tandfonline.com/ doi/pdf/10.1081/E-EEM-120047274 (accessed on 19 May 2014).

48. Micangeli, A.; Evangelisti, S.; Sbordone, D. Alternative Energy: Hydropower. In Encyclopedia of Environmental Management; Jorgensen, S.E., Ed.; Taylor and Francis Online: Oxon, UK, 2013; Chapter 23, pp. 201-214. Available online: http://www.tandfonline.com/ doi/pdf/10.1081/E-EEM-120047189 (accessed on 19 May 2014).

49. Micangeli, A.; Cataldo, M. Micro Hydro in Emergency Situations: ASustainable Energy Solution at La Realidad (Chiapas, Mexico). In Handbook of Sustainable Engineering; Kauffman, J., Lee, K.M., Eds.; Springer: Heidelberg, Germany, 2013; pp. 163-179.

50. Micangeli, A.; Grego, S.; Esposto, S. Sustainable Rehabilitation of Water Infrastructures in Southern Iraq After the Second Gulf War. In Handbook of Sustainable Engineering; Kauffman, J., Lee, K.M., Eds.; Springer: Heidelberg, Germany, 2013; pp. 211-245.

51. Micangeli, A.; Iannuzzo, N.; Esposto, S. Chlorine Self-Production Plant Solution for Effluent Water to be Used in Irrigation in Gaza Strip. In Handbook of Sustainable Engineering; Kauffman, J., Lee, K.M., Eds.; Springer: Heidelberg, Germany, 2013; pp. 117-136.

(c) 2014 by the authors; licensee MDPI, Basel, Switzerland. This article is an open access article distributed under the terms and conditions of the Creative Commons Attribution license (http://creativecommons.org/licenses/by/3.0/). 